\title{
LA REPARACIÓN CIVIL POR DAÑO MORAL EN LOS DELITOS DE PELIGRO CONCRETO
}

\author{
FLOR DE MARÍA MADELAINE POMA VALdIVIESO*
}

\section{Resumen}

El presente artículo analiza la viabilidad de que el Juez Penal imponga como sanción jurídico-penal una reparación civil por daño moral en los delitos de peligro concreto. Para ello, se examina los postulados de la responsabilidad civil hasta llegar al estudio de los delitos de peligro concreto. Finalmente, se concluye con algunos criterios que permitirían determinar el quantum del daño moral.

Palabras clave: Reparación civil - Daño moral - Delitos de peligro Cuantificación del daño moral.

\begin{abstract}
This article analyzes whether it is feasible for a Criminal Judge to dictate a civil redress, as a legal and criminal punishment, for moral damages in specific crimes of endangerment. To this effect, hypotheses of civil liability and the specific crimes of endangerment are examined, concluding with a few criteria that will allow us to determine the quantum of the compensation for moral damages.
\end{abstract}

Key words: Civil Redress - Moral Damages - Crimes of Endangerment Quantification of moral damages.

\section{Sumario}

1.- Introducción. 2.- Nociones preliminares. 3.- Concepto de Reparación Civil. 4.- El daño como elemento configurador de la Reparación Civil. 5.- Concepto de "Daño moral". 6.- Naturaleza de la reparación del daño moral. 7.- El "daño moral" en la legislación peruana. 8.- El daño moral y la reparación civil derivada del delito. 9.- Clasificación de los tipos penales. 10.- Delitos de lesión y delitos de peligro. 11.- Noción de peligro. 12.- La reparación civil por daño moral en los delitos de peligro. 13.- La Reparación civil por daño moral en los delitos de peligro concreto. 14.- Cuantificación del daño moral. 15.- Conclusiones.

\footnotetext{
* Juez Superior Titular de la Corte Superior de Justicia de Lima - Poder Judicial del Perú.
} 
Flor de María Madelaine Poma Valdivieso

La reparación civil por daño moral en los delitos de peligro concreto

\section{INTRODUCCIÓN}

La determinación de la reparación civil (por lucro cesante, daño emergente y/o daño moral) en los procesos penales es uno de los aspectos menos desarrollados en las resoluciones judiciales, pues carece de una idónea fundamentación y debida motivación. Asimismo, otro terreno aún no explorado en la dogmática penal lo constituye la reparación civil por daño moral, máxime cuando su cuantificación resulta dificultosa para el juzgador al momento de imponer una sanción indemnizatoria. No obstante, a efectos del presente trabajo de investigación, hemos decidido analizar si resulta viable fijar una reparación civil por daño moral en los delitos de peligro concreto, en razón al Acuerdo Plenario Nº 6-2006/CJ-116, el mismo que señala que sí resulta viable la fijación de reparación civil en los delitos de peligro.

\section{NOCIONES PRELIMINARES}

La reparación civil es una de las consecuencias jurídicas del delito, que se le impone -conjuntamente con la pena- a la persona que se encuentra responsable de la comisión de un delito. Si bien no es una consecuencia jurídica indispensable al momento de imponerse una pena, sí configura un mecanismo de satisfacción de intereses de la víctima, cuando se aprecie la existencia de un daño ${ }^{1}$; en ese sentido, cabe mencionar que la reparación civil no siempre se determina con la pena, pues ésta solo requiere de la existencia de una conducta típica, antijurídica y culpable, mientras que la reparación civil exige la constatación de un daño ${ }^{2}$. Asimismo, como institución jurídica se constituye como el punto de conexión entre el Derecho penal y el Derecho civil, ya que de esta manera se aprecia la doble acción de las consecuencias jurídicas del delito: pena y reparación; en otros términos, una consecuencia jurídica dirigida a restablecer la paz en la sociedad (pena) y otra dirigida a reparar el daño ocasionado a la víctima (reparación civil) ${ }^{3}$.

1 Es necesario dejar en claro que, la reparación civil no siempre se determina con la pena, pues no toda sentencia condenatoria que acaba imponiendo una sanción penal (pena o medida de seguridad), supone que se halla producido de manera efectiva un daño, que es el presupuesto básico para la fijación de la reparación civil.

2 En términos del penalista colombiano Fernando VELÁSQUEZ VELÁsQUEZ, "El hecho punible origina no solo consecuencias de orden penal sino también civil, por lo cual -en principio- toda persona que realice una conducta típica, antijurídica y culpable, trátese de imputable o inimputable, debe restituir las cosas al estado en que se encontraban en el momento anterior a la comisión del ilícito, cuando ello fuere posible, y resarcir los daños o perjuicios ocasionados al perjudicado; nace de esta manera la responsabilidad civil derivada del hecho punible". Vid. VelásQueZ VeLÁsQueZ, Fernando. Derecho penal. Parte general. Bogotá: Editorial Temis, 1997, p. 774

3 Vid. Peña Cabrera Freyre, Alonso. "Naturaleza jurídica de la reparación civil ex delicto". Gaceta Penal E Procesal Penal. 2010. № 9, p. 74: "La justicia penal ampara también el interés de la víctima (el agraviado u ofendido) con la "reparación civil" de los efectos perjudiciales de la conducta criminal. Esto se explica 
Flor de María Madelaine Poma Valdivieso

La reparación civil por daño moral en los delitos de peligro concreto

\section{CONCEPTO DE REPARACIÓN CIVIL}

Al responsable penal de un delito no sólo el Magistrado le impone una pena como consecuencia jurídica, sino también un monto de reparación civil siempre que el agraviado haya sufrido un daño, perjuicio o menoscabo. Por ello, mediante la reparación civil se busca resarcir el daño ocasionado a la víctima, en razón de restituirle al status anterior al desarrollo del suceso delictivo ${ }^{4}$. Por lo que se puede entender que la reparación civil tiene como finalidad colocar a la víctima en una posición lo más parecida posible a la que tenía antes de que se produjera el daño ${ }^{5}$. Como lo señaló Carlos FONTÁN BALESTRA, “El daño causado por el delito puede distinguirse, por lo común, en público y privado. El primero se traduce en la alarma social que el hecho delictuoso provoca; el segundo es el perjuicio o daño causado a las particulares víctimas del delito $\mathrm{o}$ a las personas a quienes las leyes reconocen el carácter de damnificados. El daño público o colectivo determina la aplicación de las medidas específicas del Derecho Penal, en primer lugar, la pena; el daño privado motiva también el resarcimiento de ese daño que se persigue con la acción civil" ${ }^{16}$. De esta manera, el daño público se encuentra compensado a través de la imposición de una pena al autor de un delito, mientras que el daño privado se compensa mediante la imposición de una obligación jurídica de reparar el daño ocasionado. En esta última encuentra su lugar la reparación civil o la responsabilidad civil derivada del delito ${ }^{7}$.

porque, como anota Raúl PEÑA CABRERA, el hecho delictivo, además de ser un ilícito penal constituye un ilícito civil, aunque no siempre es así".

4 Vidal La Rosa SÁNCHEZ, María Delfina. "La reparación civil ex delicto en los delitos de peligro abstracto". Ágora. Revista de Derecho. 2007-2008. Años IV-VI, No. 7 y 8, p. 274: "El responsable penal de un delito se le impone el cumplimiento de una pena proporcionada al mismo y destinada a fines colectivos y/o estatales, como son la finalidad preventivo-general y especial. En cambio, esa relación de carácter imperativo entre el Estado y el responsable penal no es la que caracteriza a la responsabilidad civil derivada del delito, aunque también se declare en la sentencia y sea exigible ejecutoriamente. En efecto, mientras que con la pena el responsable penal responde frente al Estado y la colectividad, con la responsabilidad civil se pretende, a grandes rasgos, reparar o compensar los efectos que el delito ha tenido sobre la víctima o los perjudicados por el mismo".

5 ZAMORA BARBOZA, Juan Rodolfo. "La determinación judicial de la reparación civil". Actualidad Jurídica. Marzo. 2009. N 184, p. 145.

6 Fontán Balestra, Carlos. Derecho penal. Introducción y Parte General. Buenos Aires: Abeledo-Perrot, 1998, p. 657 y ss. En el mismo sentido, Alfredo ETCHEBERRY señala que "El derecho penal se ocupa esencialmente de los requisitos y circunstancias que justifican la imposición de penas, esto es, de sanciones que significan una pérdida o disminución de derechos individuales para el transgresor de una norma. Estas sanciones se imponen por la especial gravedad que la ley atribuye a determinadas infracciones, que la lleva a conminar la transgresión con la reacción más severa que el derecho contempla. Otras normas, en cambio, llevan aparejadas otras sanciones, menos graves, para el caso de transgresión. En tales casos, por lo general la infracción solamente acarrea el cumplimiento forzado de lo incumplido y la reparación de los perjuicios que este incumplimiento haya producido a otro. La finalidad de estas sanciones es el restablecimiento de una situación existente con anterioridad o la creación de una situación nueva de conformidad con lo que la ley ordenaba". Vid. ETCHEBERRY, Alfredo. «Derecho Penal. Parte General». Tomo Segundo. Carlos E. Gibbs A., Editor, Santiago de Chile, 1964, p. 261.

7 En palabras de Francisco MuÑOz CONDE se tiene que "al responsable penal de un delito se le impone el cumplimiento de una pena proporcionada al mismo y destinada a fines colectivos y/o estatales, como será 
Flor de María Madelaine Poma Valdivieso

La reparación civil por daño moral en los delitos de peligro concreto

El penalista peruano REYNA ALFARO ha señalado que "La realización de un hecho punible genera no sólo consecuencias jurídico-penales en el autor del hecho (penas o medidas de seguridad), sino también consecuencias jurídicociviles que se conocen comúnmente como reparación civil"8, mientras que, por su parte, Alonso PEÑA CABRERA refiere que "La reparación civil de las consecuencias perjudiciales del hecho punible tiene que ver con la necesidad de reparar, resarcir aquellos daños causados de forma antijurídica y no con ejercer una comunicación disuasiva a los comunitarios ni con rehabilitar a quien incurrió en el delito, máxime, si la responsabilidad civil puede recaer sobre personas (naturales o jurídicas) que intervinieron en la infracción" ${ }^{\prime \prime}$.

El civilista peruano Juan ESPINOZA ESPINOZA define a la reparación civil como "la obligación que se le impone al dañante (una vez acreditado que se ha configurado un supuesto de responsabilidad civil) en beneficio del dañado, consistente, bien en una prestación de dar una suma dineraria (indemnización por equivalente) o en una prestación de hacer o de no hacer (indemnización específica o in natura). Sin embargo estas prestaciones no son excluyentes entre sín 10 .

La jurisprudencia nacional ha establecido que "la reparación civil comprende el daño causado por el delito, así como el daño emergente y el lucro cesante. (...) la comisión de todo delito acarrea como consecuencia no sólo la imposición de una pena, sino también da lugar al surgimiento de la responsabilidad civil por parte del autor, es por ello que en aquellos casos en que la conducta del agente ocasione un daño reparable, corresponde fijar junto con la pena el monto de la reparación civil"11. En ese sentido, SILVA SÁNCHEZ señala que "la reparación civil tiene como fundamento el daño y no la configuración de la conducta, es transmisible mortis causa y es asegurable"12.

la finalidad preventivo general y especial. En cambio, en la relación de carácter imperativo entre el Estado y el responsable penal no es la que caracteriza a la responsabilidad civil derivada del delito, aunque también se declare en la sentencia y sea exigible ejecutoriamente; en efecto, mientras que con la pena, el responsable penal responde frente al Estado y la colectividad, con la responsabilidad civil se pretende, a grandes rasgos, reparar o compensar los efectos que el delito ha tenido sobre la víctima o los perjudicados por el mismo". Vid. MuÑoz CONDE, Francisco y Mercedes GARCíA ARÁN. «Derecho Penal. Parte General». Tirant lo Blanch, $2^{\circ}$ edición, Valencia, 1996, p. 617-618.

8 REYNA Alfaro, Luis Miguel. «Estudio final: la víctima en el sistema penal». En: ReYNA ALFARO, Luis Miguel (Coord.). La víctima en el sistema penal. Dogmática, proceso y política criminal. Lima: Editorial Jurídica Grijley, 2006., p.147.

9 Peña Cabrera Freyre, Alonso. «Naturaleza jurídica de la reparación civil ex delicto». Gaceta Penal \& Procesal Penal, 2010, N 9, p. 82.

10 EspinOza EspinOzA, Juan. «Derecho de la Responsabilidad Civil». Lima: Gaceta Jurídica, 2006, p. 277.

11 Vid. Sentencia de la Primera Sala Penal de Apelaciones de La Libertad, recaída en el Exp. N 411-2008, de fecha once de setiembre del año dos mil ocho, fundamentos jurídicos 5 y 6 .

12 SILVA SÁNCHEZ, Jesús-María. «Sobre la relevancia jurídico-penal de la realización de actos de "reparación"». En: REYNA AlfARO, Luis Miguel (Coord.). Victimología y Victimodogmática. Una aproximación al estudio de la 
Flor de María Madelaine Poma Valdivieso

La reparación civil por daño moral en los delitos de peligro concreto

Asimismo, la Corte Suprema de Justicia ha sostenido que "la institución de la reparación civil tiene como objeto, reparar o compensar los efectos que el delito ha tenido sobre la víctima o perjudicados, reconociéndose en la dogmática jurídico-penal que los hechos que constituyen delito penal merecen la aplicación de una pena, puesto que estos hechos pueden causar un daño (...), decimos que son fuentes de responsabilidad civil, estos son por tanto casos de responsabilidad civil derivada del ilícito penal, por ende no tiene fundamento la responsabilidad en el delito sino en el daño ocasionado a la víctima, existiendo acuerdo mayoritario en la doctrina sobre su naturaleza civil y no penal de responsabilidad civil ex delito, consecuentemente para fijarlo el colegiado debió analizar el grado del daño ocasionado, debiendo guardar proporción con la entidad de los bienes jurídicos que se afectan; por lo que en el caso de autos amerita aumentar la reparación civil"13.

Finalmente, apreciamos que la reparación civil es aquella consecuencia jurídica que se impone -conjuntamente con la pena- a la persona que, en calidad de autor o partícipe, cometió un delito ${ }^{14}$. En otras palabras, la reparación civil es la responsabilidad civil atribuida al acto de un delito, por lo que éste deberá responder por las consecuencias económicas de su conducta.

\section{EL DAÑO COMO ELEMENTO CONFIGURADOR DE LA REPARACIÓN CIVIL}

El análisis de los elementos de la Responsabilidad Civil nos permitirá apreciar la viabilidad de la imposición de la reparación civil por el delito cometido. El elemento más importante de la Responsabilidad Civil es el "daño", pues la existencia de éste permite el posterior análisis de los elementos restantes que configuran la Responsabilidad Civil. Es decir, la existencia de Responsabilidad

Víctima en el Derecho Penal. ARA Editores, Lima 2003, p. 309 y ss.: "La reparación en la que puede expresarse la orientación de la víctima actual en el Derecho penal ha de fundarse necesariamente en la gravedad de la conducta y del tipo subjetivo; en cambio, es perfectamente concebible su imposición en casos de ausencia de daño (...) La reparación no constituye, pues, un nuevo fin del Derecho penal, sino que es asumida por éste en tanto en cuanto contribuye al cumplimiento de los fines tradicionales del Derecho penal".

13 Vid. Torres VÁseuez, Aníbal. «Diccionario de Jurisprudencia Civil». Lima: Editora Jurídica Grijley, 2008, p. 678.

14 En palabras de SILVA SÁNCHEZ: "La reparación puede expresar, ciertamente, en determinados casos, el reconocimiento y consiguiente estabilización de la norma vulnerada suficientes para producir el efecto de confianza de la colectividad en el funcionamiento del Ordenamiento jurídico. La cuestión es, de nuevo aquí, que la reparación, con su prioritaria orientación a la víctima actual, no desborde los límites en que puede cumplir razonablemente tal misión estabilizadora para entrar en terrenos en los que se desencadenaría la desestabilización y la desconfianza. De nuevo se produciría en tal caso un sacrificio de la víctima potencial a favor de la víctima actual". Vid. SILVA SÁNCHEZ, Jesús-María. "Sobre la relevancia jurídicopenal de la realización de actos de "reparación". En: REYNA ALFARO, Luis Miguel (Coord.). Victimología y Victimodogmática. Una aproximación al estudio de la Víctima en el Derecho Penal. Lima: ARA Editores, 2003, p. 303. 
Flor de María Madelaine Poma Valdivieso

La reparación civil por daño moral en los delitos de peligro concreto

Civil respecto a un hecho ilícito, permite al juzgador imponer la reparación civil correspondiente.

En ese sentido, uno de los elementos que configura la Reparación Civil es el daño ocasionado a otra persona o la infracción normativa que se realiza a un acuerdo voluntario de partes ${ }^{15}$. Así, siguiendo las enseñanzas de Karl LARENZ, podría definirse al "daño" como aquel "menoscabo que a consecuencia de un acaecimiento o evento determinado sufre una persona ya en sus bienes vitales o naturales, ya en su propiedad o patrimonio"16.

Esta vulneración o infracción al derecho puede afectar dos modalidades de derechos: derechos patrimoniales y derechos extrapatrimoniales. Cuando se vulneran derechos patrimoniales se está vulnerando todos aquellos bienes que otorgan un beneficio económico a su titular, generándose así la institución jurídica denominada responsabilidad civil contractual; mientras que cuando se vulneran derechos inherentes a la personalidad, como el derecho a la integridad física y el honor, se estaría violentando derechos extrapatrimoniales, permitiendo la configuración de la institución jurídica denominada responsabilidad civil extracontractual.

Por estos motivos, el Tribunal Constitucional ha determinado que "Cuando el daño es consecuencia del incumplimiento de una obligación voluntaria, se habla en términos doctrinarios de responsabilidad civil contractual, y dentro de la terminología del código Civil Peruano de responsabilidad derivada de la inejecución de obligaciones. Por el contrario, cuando el daño se produce sin que exista ninguna relación jurídica previa entre las partes, o incluso existiendo ella, el daño es consecuencia, no del incumplimiento de una obligación voluntaria, sino simplemente del deber jurídico genérico de no causar daño a otro, nos encontramos en el ámbito de la denominada "responsabilidad civil extracontractual"'"17.

\footnotetext{
15 “La noción jurídica de daño se configura en términos de daño injusto; el daño así entendido es necesariamente elemento del ilícito porque el elemento en cuanto tal comporta la lesión de un interés tutelado; el daño debe ser causalmente vinculado al comportamiento del agente o a la actividad del responsable; y se puede hacer empleo del nexo causal para seleccionar los daños resarcibles". Vid: VALDERRAMA MOYA, Karina Haydee. "Fundamentos para la cuantificación del Daño Moral". Revista ESDEN. 2007. Año: 1, No. 2, p. 185.

16 Derecho de obligaciones, versión española de J. SANTOS BRIZ, Tomo I, pág. 193. Siguiendo lo estipulado por nuestra jurisprudencia, tenemos que "[El] daño es toda lesión, disminución o menoscabo sufrido en un bien jurídico, entendiendo por tales no solo los objetivos susceptibles de ser evaluados pecuniariamente, sino también los bienes que por no tener una traducción adecuada en dinero, escapan a la esfera del patrimonio. Esos bienes no patrimoniales son de naturaleza especial, y forman en su conjunto lo que la persona es: la vida, la salud, la integridad física, el honor, la libertad, etc". Vid. Casación No. 3973-2006-Lima. 13 de diciembre de 2006.

17 STC N00001-2005-AI, segundo párrafo del fundamento jurídico 17.
} 
Flor de María Madelaine Poma Valdivieso

La reparación civil por daño moral en los delitos de peligro concreto

En el marco de la responsabilidad civil extracontractual encontramos el daño moral y el daño a la persona, como instituciones dirigidas a compensar el daño ocasionado al vulnerar la norma genérico del neminem laedere (no dañar a otro), conforme lo reconoce el artículo $1985^{\circ}$ del Código Civil ${ }^{18}$.

\section{CONCEPTO DE “DAÑO MORAL”}

Una de las definiciones más complicadas en el ámbito de la Responsabilidad civil es el referido al "daño moral", pues su definición entregaría las nociones básicas y elementales para lograr la cuantificación de su compensación. Por ello MÉNDEZ ROZO señala que "Ese daño moral debe ser cuantificado para reparar de forma total y eficiente al individuo vulnerado y así, permitir que el camino jurídico de las normas, se desenvuelva de forma natural y evolutiva"19.

Por estas consideraciones, se define al "daño moral" como aquella "modificación disvaliosa del espíritu en el desenvolvimiento de su capacidad de entender, querer, o sentir, que se traduce en un modo de estar de la persona diferente de aquél en que se hallaba antes del hecho, como consecuencia de éste y anímicamente perjudicial" ${ }^{20}$.

Por su parte el jurista español DíEZ-PICAZO señala que "el denominado daño moral debe reducirse al sufrimiento o perturbación de carácter psicofísico en el ámbito de la persona" ${ }^{21}$, señalando así al sufrimiento y a la perturbación psíquica y física de la persona como elementos constitutivos del daño moral.

Lajurisprudencia peruana define esta institución como "el daño no patrimonial inferido en derechos de la personalidad o en valores que pertenecen más al campo de la afectividad que al de la realidad económica; en cuanto a sus efectos, es susceptible de producir una pérdida pecuniaria y una afectación espiritual" 22 .

\footnotetext{
18 "[El] citado artículo $1985^{\circ}$ del Código Civil contempla como daño no patrimonial el daño a la persona y el daño moral, entendiéndose por el primero de ellos el que se configura como una afectación de los derechos de la personalidad; y el segundo, como el dolor o la angustia que experimenta una persona a causa de un evento dañoso, existiendo entre ambos conceptos una relación de género a especie, según lo ha destacado el doctor Carlos FERNÁNDEZ SESSAREGO, en cuanto ha sostenido que el daño moral, dentro de su concepción dominante de dolor o sufrimiento, constituye un aspecto del daño a la persona". Vid. Casación No. 1545-3006-Piura; Sala Civil de la Corte Suprema, Lima, 14 de noviembre de 2006.

19 Méndez Rozo, Diana Cecilia. "El daño moral como límite a la libertad de prensa (Reflexiones desde el Derecho colombiano y el Derecho comparado)". REDUR. 1999. Diciembre. No. 7, p. 86.

20 Valderrama Moya, Karina Haydee. "Fundamentos para la cuantificación del Daño Moral". Revista ESDEN. 2007. Agosto/Octubre, Año: 1, No. 2, p. 185.

21 Díez- Picazo Y Ponce De León, Luis. Derecho de daños. Madrid: Editorial Civitas, 2000, p. 328.

22 Casación No. 1070-95-Arequipa, Sala Civil de la Corte Suprema, 13 de julio de 1998. En palabras del jurista peruano Osterling PARODI, "El daño moral es el daño no patrimonial; es el inferido en derechos de la
} 
En palabras de MÉNDEZ ROZO, en la jurisprudencia colombiana definen al "daño moral" como "el integrante de la lesión que padece la víctima, está concebido como el dolor humano o sufrimiento que ésta experimenta y que dada su naturaleza corresponde al mundo de la sensibilidad espiritual y mantiene relación directa con la dignidad del ser humano"23.

De esta manera, puede apreciarse que el "daño moral" tiene un elemento netamente subjetivo ${ }^{24}$, es decir, que su fundamento se encuentra en aquel daño que logra ocasionar un menoscabo en su integridad psíquica; por lo que, sus efectos dependerían de los diversos estados psicológicos del sujeto, pues este tipo de daño se encuentra en proporción directa con la parte afectiva del ser humano ${ }^{25}$.

Sin embargo, resulta interesante el concepto elaborado por el jurista chileno Marcelo MONTERO, quien determina que "podemos entender por daño moral cualquier interferencia no consentida, ilegal o arbitraria, en el plan de vida de una persona o en el desarrollo institucional de una persona jurídica" 26 .

\section{NATURALEZA DE LA REPARACIÓN DEL DAÑO MORAL}

Existen tres vertientes que pretenden explicar la naturaleza del "daño moral": a) la tesis punitiva; b) la tesis resarcitoria; y, c) la tesis mixta. La primera de estas tesis, refiere que la reparación del "daño moral" constituye una sanción al ofensor y considera que "los derechos así lesionados tienen una naturaleza ideal no susceptibles de valoración pecuniaria y, por ello, no son resarcibles: lo que mira en realidad la condena, no es la satisfacción de la víctima, sino el castigo del autor, los daños e intereses no tienen carácter resarcitorios sino ejemplar" 27.

De otra parte, la tesis resarcitoria considera que la reparación del "daño moral" cumple con la función de satisfacción de la responsabilidad civil,

persona o en valores que pertenecen más al campo de la afectividad que al de la realidad económica, (...) y, en cuanto a sus efectos, son susceptibles de producir una pérdida pecuniaria, o son morales strictu sensu, cuando el daño se refiere a lo estrictamente espiritual". Vid. OsTERLING PARODI, Felipe. Tratado de Obligaciones. Lima: Gaceta Jurídica, 2005, p. 292

23 MÉndez Rozo, Diana Cecilia. Op. cit., p. 87.

24 "El dolor, la pena, la angustia, la inseguridad, etc., son solo elementos que permiten aquilatar la entidad objetiva del daño moral padecido, el que se produce en un solo acto o en varios, pero que una vez presentados en el contexto fáctico ya son susceptibles de indemnizarse, es decir, de reparación indirecta con dinero". Vid. Casación No.959-95-Arequipa, 18 de diciembre de 1997.

25 MÉndez Rozo, Diana Cecilia. Op. cit., p. 88.

26 Montero, Marcelo. "Responsabilidad Civil y daño moral". Apuntes de Derecho. Setiembre. 2001. No 8, p. 23.

27 Vielma MendozA, Yoleida. "Discusiones en torno a la reparación del daño moral". Dikaiosyne. 2006. No. 16. Revista de filosofía práctica, p. 147. 
Flor de María Madelaine Poma Valdivieso

La reparación civil por daño moral en los delitos de peligro concreto

siendo que "proporcionar al lesionado o perjudicado una satisfacción por la aflicción y la ofensa que se le causó, que le otorgue no ciertamente una indemnización propiamente dicha o un equivalente mensurable por la pérdida de su tranquilidad y placer de vivir, pero sí una cierta compensación por la ofensa sufrida y por la injusticia contra él personalmente cometida" 28 .

Finalmente, la tesis mixta plantea que "La reparación del daño moral puede revestir y reviste comúnmente, el doble carácter de resarcitorio para la víctima y de sanción para el agente del ilícito que se atribuye" ${ }^{\prime 29}$. De esta manera, se aprecia que la reparación del "daño moral" presenta una naturaleza doble, dependiendo de la persona que reciba los efectos de la reparación.

Asimismo, siguiendo lo anotado por MÉNDEZ ROZO, el daño moral puede ser reparado de dos maneras: reparación in natura o específica, y resarcimiento pecuniario. Desde la perspectiva de la reparación in natura, ésta se refiere a restituir el estado que el sujeto tenía antes de la comisión del daño. Si bien parece poco verosímil esta posición, se considera que para casos de información que emite la prensa, ésta puede resarcirse a través de un comunicado expresando la corrección de su error; en otras palabras, este tipo de restitución consiste en volver las cosas al estado anterior al acto dañoso, consistiendo en una obligación de hacer. Asimismo, el resarcimiento pecuniario se intenta conseguir, en mayor o menor medida, sustituir el bien dañado por su valor monetario ${ }^{30}$, consistiendo en el pago de una suma de dinero que represente simbólicamente el valor del daño experimentado, constituyéndose como una obligación de dar.

\section{EL “DAÑO MORAL” EN LA LEGISLACIÓN PERUANA}

En el Código Civil de 1852 se ignoraba la existencia de esta institución debido a la influencia francesa del Code de Napoleón, ya que en ésta el Derecho Civil está orientado a la reparación; sin embargo, se aprecia en el artículo 2202 que

\footnotetext{
${ }^{28}$ LarenZ, Karl. Derecho de obligaciones, Traducción de J. Santos Briz. Madrid: Revista de derecho Privado, 1959, pp. 642 y ss.

29 “La reparación cumple, entonces, una función de justicia correctiva o sinalagmática, que conjuga o sintetiza a la vez la naturaleza resarcitoria de la indemnización del daño moral para la víctima (entidad del bien jurídico lesionado, su posición social, la repercusión del daño en su ser existencial individual o personal y también de relación intersubjetiva, etc,) y la naturaleza punitoria o sancionatoria de la reparación para el agente del daño (su mayor deber de prever las consecuencias del hecho ilícito, su situación económica, el factor de atribución de responsabilidad, etc).". Vid. VIELMA MENDOZA, Yoleida. "Discusiones en torno a la reparación del daño moral". Dikaiosyne. 2006. No. 16. Revista de filosofía práctica, pp. 149-150.

30 "Desde el punto de vista de la víctima, la indemnización debe ser suficiente, compensatoria, no instituir diferencias irritantes e irreales con montos indemnizatorios para víctimas de daños similares; y lograr que su pago sea en forma más o menos inmediata". Vid. MÉNDEZ ROZO, Diana Cecilia. Op. cit., pp. 101-102.
} 
Flor de María Madelaine Poma Valdivieso

La reparación civil por daño moral en los delitos de peligro concreto

el legislador señala que "En caso de injurias, tiene derecho el que las recibe a pedir una indemnización proporcionada a la injuria", el mismo que podría entenderse como una forma originaria de indemnización por daño moral ${ }^{31}$.

No obstante, en el Código Civil de 1936, se logra reconocer el "daño moral" como institución jurídica en su artículo $1148^{\circ}$, al señalar que "al fijar el Juez la indemnización, puede tomar en consideración el daño moral irrogado a la víctima", logrando su aparición en nuestro ordenamiento jurídico. Asimismo, en la Exposición de Motivos del Libro Quinto del Proyecto del Código Civil de 1936 los legisladores manifestaron: "No es preciso [...] que el daño sea material o patrimonial. Puede tratarse de verdaderos detrimentos morales que se traducen en dolores o menoscabos de ciertos bienes inmateriales. No nos han parecido bastantes las observaciones relativas al carácter pasajero de estas situaciones, ni las dificultades invocadas para relacionar los daños morales y las indemnizaciones. A través de estas y de otras observaciones, la institución se ha instalado en los Códigos modernos y tiene su desarrollo en la jurisprudencia de los tribunales. La actitud prudente de nuestra formulación puede ser notada en el hecho de bienes atribuido al juez la facultad de influenciar la indemnización por el factor moral que hubiere intervenido. Por este medio la jurisprudencia estará habilitada a reparar o a satisfacer todos los intereses respetables. Habrán casos sin duda en los que la solución indicada sea la de dar satisfacción a los sentimientos de la persona humana, o al perjuicio de ciertos aspectos de los bienes no materiales" 32 .

El daño moral se encuentra regulado en nuestro Ordenamiento jurídico civil vigente, tanto en las normas correspondientes a la responsabilidad contractual como a las normas de la responsabilidad extracontractual. Para su inclusión en el Código Civil actual se dieron las razones: "De un lado, el hecho de que, aun cuando se trate de una reminiscencia de sentimientos primitivos de venganza, un país tiene que darse un Código a su medida, y si en el Perú la víctima de un "daño moral" espera que se imponga una indemnización al culpable, es necesario que el Derecho atienda de alguna manera esta necesidad

${ }^{31}$ De Trazegnies, Fernando. La Responsabilidad Extracontractual. Lima: Fondo Editorial de la Pontificia Universidad Católica del Perú, 1988, p. 101.

32 Vid. LEÓN, Lyesser. «Funcionalidad del "daño moral" e inutilidad del "daño a la persona" en el derecho civil peruano". Diké. Portal de Información y Opinión Legal de la Pontificia Universidad Católica del Perú. Disponible en Internet: http://dike.pucp.edu.pe/doctrina/civ_art57.PDF Asimismo, DE TRAZEGNIES, Fernando. La Responsabilidad Extracontractual. Lima: Fondo Editorial de la Pontificia Universidad Católica del Perú, 1988, p. 101.: “El Código Civil de 1936 reconoce el daño moral extracontractual en su artículo 1148, pero tímidamente: se limita a señalar que el juez "puede" tomar en consideración el daño moral. A su vez, con el mismo carácter facultativo para el juez, lo autoriza a fijar una indemnización por daño moral en los casos de ruptura de esponsales (artículo 79). Nada se dice sobre daño moral en relación con la responsabilidad contractual". 
psicológica. De otro lado, a veces el daño moral sirve para indemnizar aquello que la doctrina ha denominado "daños patrimoniales indirectos", es decir, aquellos daños que, siendo económicos, son difícilmente valorizables: el demandante no puede probar su monto preciso" ${ }^{\prime 33}$.

Asimismo, desde la perspectiva de la responsabilidad contractual, encontramos el artículo $1322^{\circ}$ del C.C. referido a la "Indemnización por daño moral" en la que se lee: "El daño moral, cuando él se hubiera irrogado, también es susceptible de resarcimiento", señalando expresamente la existencia de daño moral en la vulneración de los derechos patrimoniales.

Finalmente, y de manera más específica, el artículo $1984^{\circ}$ del C.C. establece que "El daño moral es indemnizado considerando su magnitud y el menoscabo producido a la víctima o a su familia", configurando así su estrecha relación con la vulneración de los derechos extrapatrimoniales, referidos a la responsabilidad extracontractual.

\section{EL DAÑO MORAL Y LA REPARACIÓN CIVIL DERIVADA DEL DELITO}

La reparación del daño moral ocasionado en el agraviado y/o perjudicado no solo es viable en el ámbito del Derecho civil, sino también es factible en el ámbito del Derecho penal. El fundamento de esta institución jurídica es diferente en ambas ramas del Derecho, pues mientras en el Derecho civil surge por la infracción de una norma jurídica, en el Derecho penal -según la doctrina mayoritaria- se requiere la comisión y existencia de un hecho típico penalmente para que éste sea merecedor de una reparación civil.

No obstante, siguiendo al civilista peruano Leysser LEÓN comprendemos que "Para el caso del daño moral, se ha sostenido que la función de la responsabilidad civil es más bien aflictivo-consolatoria, mitigadora del sufrimiento, debido a la imposibilidad de "reparar" éste, en sentido estricto: "La función eminentemente aflictivo-consolatoria del resarcimiento del daño extrapatrimonial queda así configurada como una manifestación de la función satisfactoria de la responsabilidad civil desde una perspectiva diádica, en detrimento de la afirmación de una función reparatoria de aquél"'"34.

\footnotetext{
33 DE TRAZEgnies, Fernando. «La Responsabilidad Extracontractual». Fondo Editorial de la Pontificia Universidad Católica del Perú, Lima 1988, p. 107.

34 Vid. LEÓN, Leysser. "Funcionalidad del "daño moral" e inutilidad del "daño a la persona" en el derecho civil peruano". Diké. Portal de Información y Opinión Legal de la Pontificia Universidad Católica del Perú. Disponible en Internet: http://dike.pucp.edu.pe/doctrina/civ_art57.PDF. Asimismo, siguiendo a Adolfo DI MAJO
} 
Flor de María Madelaine Poma Valdivieso

La reparación civil por daño moral en los delitos de peligro concreto

De esta manera, para conocer la viabilidad de la existencia de una reparación civil por "daño moral" en la comisión de un delito consideramos necesario revisar los diversos tipos penales que describen los elementos normativos que constituyen la existencia de un delito.

\section{CLASIFICACIÓN DE LOS TIPOS PENALES}

En la doctrina especializada encontramos que los tipos penales se clasifican según su estructura (tipo básico y tipos derivados), por su relación entre la acción y el objeto de la acción (tipos de resultado y tipos de mera actividad), por el daño del objeto de la acción (tipos de lesión y tipos de peligro, ya sea concreto o abstracto), por las formas básicas de comportamiento (tipos de comisión y tipos de omisión), por el número de bienes jurídicos protegidos (tipos monofensivos y pluriofensivos), por el número de agentes (tipos individuales y tipos colectivos), por las características del agente (tipos comunes y tipos especiales) ${ }^{35}$.

La primera clasificación hace referencia al dispositivo legal genérico y al derivado, es decir, a aquel tipo penal que describe la acción (Artículo $188^{\circ}$ del C.P.) y a aquel tipo penal que señala las acciones o circunstancias que agravan la acción (Artículo $189^{\circ}$ del C.C.); asimismo, la segunda clasificación se refiere a la consumación y grados de consumación del delito. También encontramos que los tipos penales se clasifican según su obrar, es decir, si es una conducta comitiva (de hacer 'algo') o si es una conducta omitiva (de no hacer 'algo'), aquellos tipos penales que protegen diversos bienes jurídicos o uno solo, y aquellos tipos penales que describen la conducta de una persona cualquiera o de aquella que cumple un papel especial en el desempeño de la sociedad.

Sin embargo, sin perjuicio de los tipos penales antes reseñados, consideramos necesario analizar si los tipos penales clasificados por el daño del objeto de la acción son merecedores de una reparación, teniendo en consideración que estos hacen referencia al daño como característica principal de su clasificación, en razón del Acuerdo Plenario $\mathrm{N}^{\circ}$ 6-2006-CJ/116 referido a la reparación civil y los delitos de peligro.

señala que: "prefiere hablar de función compuesta, porque, "por un lado, se tiende a brindar una forma de satisfacción y/o gratificación a la víctima del hecho ilícito, en el sentido de asegurarle un beneficio económico -y al respecto, es innegable que el dinero también puede servir para dicho fin- y, por otro lado, para sancionar el comportamiento del responsable de la infracción"'".

35 Muñoz CONDE, Francisco y Mercedes GARCía ARÁN. «Derecho Penal. Parte General». Tirant lo Blanch, 4ta edición, Valencia: 2000, pp. 291 y ss; FONTÁn BALESTRA, Carlos. «Derecho Penal. Introducción y Parte General». Abeledo-Perrot, 16ta edición, Buenos Aires 1998, pp. 243 y ss. 
Flor de María Madelaine Poma Valdivieso

La reparación civil por daño moral en los delitos de peligro concreto

\section{DELITOS DE LESIÓN Y DELITOS DE PELIGRO}

Desde la perspectiva de esta clase de delitos, la doctrina reconoce que el bien jurídico puede ser afectado de dos formas: de lesión y de peligro. En palabras del jurista argentino Eugenio Raúl ZAFFARONI "Hay daño o lesión cuando la relación de disponibilidad entre el sujeto y el ente se ha afectado realmente, es decir, cuando se ha impedido efectivamente la disposición, sea en forma permanente (como sucede en el homicidio) o en forma transitoria. Hay afectación del bien jurídico por peligro cuando la tipicidad requiere solamente que esa relación se haya puesto en peligro. Estas dos formas de afectación dan lugar a una clasificación de los tipos penales en tipos de daño y tipos de peligro"36.

En el mismo sentido, el jurista español MUÑOz CONDE señala que "Normalmente, la forma consumada de los tipos delictivos contiene una lesión del bien jurídico protegido en dicho tipo. [Sin embargo,] junto a la lesión, en el Derecho penal se castiga también la puesta en peligro de bienes jurídicos" ${ }^{\prime 37}$. En otras palabras, no solo la conducta que ocasiona un daño material sobre un bien jurídico es merecedora de una sanción penal, sino también aquella conducta que pone en peligro la integridad del bien jurídico.

Respecto a los delitos de lesión o daños, nuestra jurisprudencia ha sostenido que "En el delito de daños, el comportamiento consiste en dañar, destruir o inutilizar un bien, siendo que en su tipicidad subjetiva, se requiere necesariamente el dolo; que en tal sentido, del análisis de lo actuado, se colige claramente que al compulsar el aspecto interno de la conducta con el tipo subjetivo, se determina que en todo caso el acto es atribuible con carácter culposo, por lo que mal puede el a quo sentenciar al procesado por un delito cuya configuración es esencialmente doloso" ${ }^{38}$.

Asimismo, en cuanto a los delitos de peligro nuestros magistrados en el Acuerdo Plenario $N^{\circ}$ 6-2006/CJ-116, en su fundamento noveno, han señalado que "Los delitos de peligro - especie de tipo legal según las características externas de la acción - pueden definirse como aquellos en los que no se requiere que la conducta del agente haya ocasionado un daño sobre un objeto,

36 ZAffaroni, Eugenio Raúl. «Manual de Derecho Penal Parte General». Ediciones Jurídicas, Lima, 1990, p. 474.

37 Muñoz Conde, Francisco y Mercedes García ARÁn. «Derecho Penal. Parte General». Tirant lo Blanch, 4ta edición, Valencia 2000, p. 344.

38 Vid. Exp. Nº 6872-97, Ej. sup., 27 dic. 1997. En: LA ROSA GÓMEZ DE LA TORRE, José Miguel. «Jurisprudencia del proceso penal sumario». Editorial Grijley, Lima 1999, pp. 343-345. 
Flor de María Madelaine Poma Valdivieso

La reparación civil por daño moral en los delitos de peligro concreto

sino que es suficiente con que el objeto jurídicamente protegido haya sido puesto en peligro de sufrir una lesión que se quiere evitar (el peligro es un concepto de naturaleza normativa en cuanto a que su objeto de referencia es un bien jurídico, aunque su fundamento, además de normativo, también se basa en una regla de experiencia o de frecuente que es, a su vez, sintetizada en un tipo legal)"39.

Además, dentro de la clasificación de los delitos de peligro, la doctrina logra diferenciar los delitos de peligro concreto y los delitos de peligro abstracto. En los delitos de peligro concreto es necesario que la acción desplegada ocasione un peligro real al bien jurídico, la misma que se prueba con la existencia de un peligro efectivo ${ }^{40}$. De otra parte, en los delitos de peligro abstracto solo se necesita comprobar si se ha desarrollado una conducta prohibida ${ }^{41}$, sin necesidad de analizar en el caso concreto si se generó o no un peligro ${ }^{42}$.

39 Vid. Acuerdo plenario $N^{\circ}$ 6-2006/CJ-116, Precedente vinculante, Pleno Jurisdiccional de las Salas Penales Permanentes y Transitorias, 13 oct. 2006, en: Jurisprudencia. Diciembre. 2006. Año XV, No 857 [Boletín de El Peruano], p. 6327.

40 Vid. Vidal La Rosa Sánchez, María Delfina. «La reparación civil ex delicto en los delitos de peligro abstracto». En: Ágora. Revista de Derecho. $N^{\circ} 7$ y 8, p. 270: "al igual que ocurre con los delitos de lesión, en los delitos de peligro concreto el tipo legal prevé, como elemento constitutivo de la infracción, una modificación del mundo exterior, física y cronológicamente, diferente de la acción incriminada. Por eso, la cuestión de la causalidad y de la imputación objetiva se plantea de la misma manera que con relación a los delitos de lesión. Sin embargo, a diferencia de estos, en donde el objeto del delito (bienes, persona, etc.) es directamente afectado por el quehacer delictuoso, en los delitos de peligro concreto dicha modificación solo consiste en la creación de una situación que puede dar lugar a un perjuicio respecto al objeto del delito".

41 Vid. Vidal La Rosa SÁNCheZ, María Delfina. Op. Cit., pp. 270-271: "El denominado delito de peligro abstracto, (...) no supone alteración alguna de mundo exterior diferente e independiente de la acción en que consiste. Por lo tanto, se consuma con la realización de la acción reprimida por peligrosa".

42 Villavicencio Terreros, Felipe. «Derecho Penal. Parte General». Lima: Editorial Jurídica Grijley, 2006, pp. 311-312. Asimismo, en términos de ZAFFARONI, “(...) se distinguió entre tipos de peligro abstracto y tipos de peligro concreto. El peligro fue entendido como un verdadero peligro y el abstracto como una posibilidad de peligro. Semejante interpretación resulta insostenible, porque con ella el llamado peligro abstracto sería un "peligro de peligro", lo que en el caso de la tentativa traería la consecuencia de requerir un "peligro de peligro de peligro". En realidad, no hay tipos de peligro concreto y de peligro abstracto -al menos en sentido estricto-, sino sólo tipos en los que se exige la prueba efectiva del peligro corrido por el bien jurídico, en tanto que en otros hay una inversión de la carga de la prueba, pues realizada la conducta se presume el peligro hasta tanto no se pruebe lo contrario, circunstancia que corresponderá probar al acusado. Se trata de una clasificación con relevancia procesal más que penal "de fondo"”. ZAFFARONI, Eugenio Raúl. «Manual de Derecho Penal Parte General». Ediciones Jurídicas, Lima 1990, p. 474. En el mismo sentido, “De daño y de peligro. Los primeros suponen la disminución o destrucción de un bien jurídico, como las lesiones; los segundos están constituidos por un hecho que pone en peligro uno o más bienes jurídicos, como el que fuera de los casos permitidos por la ley fabrica, adquiere o conserva dinamita u otra materia u objetos explosivos o inflamables, o gases o bombas mortíferas o sustancias que sirvan para la composición o fabricación de ellos (artículo 260 del Código Penal)". Gaitán MAHECHA, Bernardo. «Curso de Derecho Penal General». Ediciones Lerner, Bogotá 1963, p. 111. 


\section{NOCIÓN DE PELIGRO}

La noción de peligro es importante en el ámbito jurídico, pues es el elemento que configura los denominados delitos de peligro. Su concepción no es unívoca en el ámbito del Derecho Penal; sin embargo, podemos señalar que el peligro es aquella situación en la cual se prevé la posibilidad de la producción de un daño ${ }^{43}$.

Para determinar la existencia de peligro es necesario que concurran dos requisitos: a) el peligro debe encontrarse en relación directa con el comportamiento concreto, $\mathrm{y}$ b) constatar que dicho peligro supere el riesgo permitido.

\section{LA REPARACIÓN CIVIL POR DAÑO MORAL EN LOS DELITOS DE PELIGRO.}

El Acuerdo Plenario N 6-2006/CJ-116, en su fundamento décimo, señala que cabe la posibilidad que exista reparación civil en los delitos de peligro "puesto que en ellos -sin perjuicio, según los casos, de efectivos daños generados en intereses individuales concretos- se produce una alteración del ordenamiento jurídico con entidad suficiente, según los casos, para ocasionar daños civiles, sobre el que obviamente incide el interés tutelado por la norma penal que, por lo general y que siempre sea así, es de carácter supraindividual-. Esta delictiva alteración o perturbación del ordenamiento jurídico se debe procurar restablecer, así como los efectos que directa o causalmente ha ocasionado su comisión [el daño como consecuencia directa y necesaria del hecho delictivo]".

Sin embargo, el Acuerdo Plenario en mención omite pronunciarse sobre la modalidad de delito de peligro que puede generar responsabilidad civil y, consecuentemente, su correspondiente reparación civil desde la orientación del derecho penal. Es necesario, entonces, examinar en qué casos (delitos de peligro concreto y/o delito de peligro abstracto) resulta idóneo sancionar con una reparación civil.

Si entendemos el daño moral como aquel estado de sufrimiento ocasionado por el hecho ilícito, entonces es necesario que exista una acción externa que

\footnotetext{
43 Vid. Vidal La Rosa SÁnchez, María Delfina. Op. Cit., p. 263.: "En el lenguaje común, se entiende por peligro el "riesgo o contingencia inminente de que suceda algún mal" y por situación de peligro aquella que aumenta la inminencia del daño".
} 
produzca este sentimiento. Asimismo, si el hecho ilícito se configura como hecho típico penalmente, éste puede generar un estado de sufrimiento en el agraviado o perjudicado, ya sea a través de los delitos de lesión o delitos de peligro. Es preciso mencionar que resultaría ocioso examinar si los delitos de lesión generan o no reparación civil por daño moral, pues la mayoría de delitos de nuestra normativa son catalogados como delitos de lesión y, consecuentemente, merecedores de una reparación civil por daño moral; sin embargo, es necesario detenernos en los delitos de peligro para apreciar si su configuración les permite o no ser merecedores de una reparación civil derivada del delito por daño moral.

\section{LA REPARACIÓN CIVIL POR DAÑO MORAL EN LOS DELITOS DE PELIGRO CONCRETO}

Desde la óptica civil tenemos que para la configuración de la existencia de un daño moral se requiere analizar los siguientes presupuestos ${ }^{44}$ : a) el hecho ilícito, b) el daño causado, c) la relación de causalidad, d) factores de atribución (criterios de imputación de responsabilidad civil). Cabe señalar que estos presupuestos son los mismos que emplean la doctrina y la jurisprudencia para analizar los casos que corresponden a los daños patrimoniales y daños extrapatrimoniales.

En ese sentido, tenemos que el presupuesto referido al "hecho ilícito" se entiende como aquella conducta humana que contraviene la norma y el orden jurídico. Debemos advertir que en el ámbito del Derecho civil se diferencia entre hecho ilícito típico y atípico; no obstante, ambos pueden generar daños y dar lugar a supuestos de responsabilidad civil en el ámbito penal ${ }^{45}$.

Asimismo, se requiere que luego de evaluar la conducta ilícita, sea típica o atípica, ésta debe ocasionar un daño, de manera que pueda ser viable una indemnización, siendo que "se entiende por daño la lesión a todo derecho subjetivo, en sentido de interés jurídicamente protegido del individuo en su vida de relación, que en cuanto protegido por el ordenamiento jurídico, se convierte justamente en derecho subjetivo, esto es un derecho en el sentido formal y técnico de la expresión" ${ }^{46}$.

\footnotetext{
${ }^{44}$ GuILleRMO BRINGAS, Luis Gustavo. «Aspectos fundamentales del resarcimiento económico del daño causado por el delito». Lex. Revista de Derecho. $\mathrm{N}^{\circ} 1$, pp. 515 y siguientes.

45 GuIllermo Bringas, Luis Gustavo. "Aspectos fundamentales del resarcimiento económico del daño causado por el delito". En: Lex. Revista de Derecho. № 1, p. 515.

${ }^{46}$ Citando a Lizardo Taboada, GuILlermo BrINGAS, Luis Gustavo. Op. Cit., p. 516.
} 
Flor de María Madelaine Poma Valdivieso

La reparación civil por daño moral en los delitos de peligro concreto

Otro presupuesto que debe demostrarse es la existencia de relación de causalidad entre la conducta ilícita y el daño ocasionado, de manera que deben concurrir dos factores: "el factor in concreto y el factor in abstracto. El primero debe entenderse como una causalidad física o natural, es decir, que el daño causado debe ser consecuencia natural o fáctica del hecho ilícito del autor" 47 , mientras que el segundo opera "según el curso normal y ordinario de los acontecimientos [que] deben ser capaz o adecuada para producir el daño causado" 48 .

Finalmente, se deben analizar los factores de atribución consistentes en criterios de imputación de responsabilidad civil: factores de atribución objetiva (el riesgo o peligro causado) y factores de atribución subjetivos (dolo y culpa). Por lo que, luego de analizar cada uno de estos presupuestos se tendrá la existencia de un reparación civil por daño moral.

Sin embargo, desde la perspectiva del análisis jurídico-penal, consideramos en concordancia con lo expuesto por el jurista español Jesús-María SILVA SÁNCHEZ ${ }^{49}$ que es innecesario que el daño ocasionado sea penalmente típico y que el daño causado sea reputado delictivo. En otras palabras, solo se requiere que la conducta ilícita (hecho ilícito) sea típica penalmente y que ésta genere u ocasione un daño, sin importar si el daño debe ser considerado como delito o no.

Un ejemplo palpable de la reparación civil por daño moral en los delitos de peligro concreto lo encontramos en el artículo $125^{\circ}$ del Código Penal, que tipifica la siguiente conducta: "El que expone a peligro de muerte o de grave e inminente daño a la salud o abandona en iguales circunstancias a un menor de edad o a una persona incapaz de valerse por sí misma que estén legalmente bajo su protección o que se hallen de hecho bajo su cuidado, será reprimido con pena privativa de libertad no menor de uno ni mayor de cuatro años". En efecto, la exposición a peligro y el abandono constituyen conductas ilícitas que más allá de configurarse penalmente típicas ${ }^{50}$, generan un sufrimiento en el agraviado o perjudicado; por lo que, ocasiona un daño moral en la esfera jurídica del agraviado o perjudicado. En consecuencia, queda demostrado que en los

47 GuIllermo Bringas, Luis Gustavo. Op. Cit., p. 518.

48 Guillermo Bringas, Luis Gustavo. Op. Cit., p. 518.

49 SIlva SÁnCHEZ, Jesús-María. "¿ "ex delicto"? Aspectos de la llamada "responsabilidad civil" en el proceso penal». INDRET. Julio. 2001, pp. 3 y siguientes. Disponible en Internet: www.indret.com

50 SAlinas Siccha, Ramiro. Derecho Penal. Parte Especial. Quinta edición. Lima: Grijley, 2013, p. 268.: “En todos los supuestos delictivos, el peligro debe ser concreto e inminente para la vida misma o para la salud del sujeto pasivo. Todo riesgo que no tenga estas connotaciones carece de relevancia para la presente figura delictiva, como sucedería si se verifica que el riesgo es leve o remoto". 
Flor de María Madelaine Poma Valdivieso

La reparación civil por daño moral en los delitos de peligro concreto

delitos de peligro concreto es viable la fijación de una reparación civil por daño moral.

Asimismo, el artículo $128^{\circ}$ de nuestra normativa penal requiere para su configuración la existencia de un peligro: "El que expone a peligro la vida o la salud de una persona colocada bajo su autoridad, dependencia, tutela, curatela o vigilancia, sea privándola de alimentos o cuidados indispensables, sea sometiéndola a trabajos excesivos, inadecuados, sea abusando de los medios de corrección o disciplina, sea obligándola o induciéndola a mendigar en lugares públicos, será reprimido con pena privativa de libertad no menor de uno ni mayor de cuatro años.

En los casos en que el agente tenga vínculo de parentesco consanguíneo o la víctima fuere menor de doce años de edad, la pena será privativa de libertad no menor de dos ni mayor de cuatro años.

En los casos en que el agente obligue o induzca a mendigar a dos o más personas colocadas bajo su autoridad, dependencia, tutela, curatela o vigilancia, la pena privativa de libertad será no menor de dos ni mayor de cinco años"; por lo que, cada una de las modalidades delictivas que acoge este tipo penal requiere de la producción de un peligro ${ }^{51}$, el mismo que al generar un daño en el perjudicado o agraviado constituye una reparación civil por daño moral.

De igual manera, el inciso primero del artículo $168^{\circ}$-A exige que "el peligro que ocasiona el empleador debe ser real, es decir, debe ser idóneo para afectar el bien jurídico protegido" 52 , con lo cual se estaría produciendo un daño, merecedor de una reparación civil por daño moral.

En síntesis, para la viabilidad de una reparación civil por daño moral en los delitos de peligro concreto se requiere la existencia de un daño ocasionado por la presencia de un peligro, siendo que este daño ataca a la esfera interna del agraviado y del perjudicado.

\section{CUANTIFICACIÓN DEL DAÑO MORAL}

El ámbito referido a la cuantificación del daño moral es uno de los más complicados al momento de emitir una sanción jurídica destinada a la reparación o al resarcimiento, pues el trabajo de valoración económica es diferente al que se realiza en casos de derechos patrimoniales ${ }^{53}$.

\footnotetext{
51 SAlinAs SICCHA, Ramiro. Derecho Penal. Parte Especial. Quinta edición. Lima: Grijley, 2013, pp. 286 y siguientes.

52 VILLAVICEnCITO Terreros, Felipe y Robert MEZA RIVERA. Informe legal. Análisis del delito de Atentado contra las condiciones de seguridad e higiene industriales. Disponible en Internet: www.vmrfirma.com

53 “Mientras que en el daño patrimonial la valuación se realiza mediante una relación de equivalencia y proporción entre el daño ocasionado y la consiguiente reparación, la cual ingresa en lugar del perjuicio, en
} 
Sobre la cuantificación del daño moral nuestra jurisprudencia ha señalado que "El daño moral sí es cuantificable patrimonialmente, aun cuando su valuación sea difícil, desde que el interés del acreedor puede ser patrimonial o no, cuestión que no debe confundirse con el carácter patrimonial de la obligación; el perjuicio que experimenta el acreedor no es siempre de naturaleza patrimonial, aunque con menor frecuencia el retardo o el incumplimiento pueden afectar otro género de derechos todavía más valiosos como es el daño moral" ${ }^{54}$. De esta manera, la Corte Suprema de Justicia reconoce la posibilidad de la cuantificación del daño moral en nuestro derecho, lográndose así colocar en un mejor status al agraviado frente al hecho dañoso acaecido.

En ese sentido, para establecer la dosificación del monto equivalente a una indemnización por daño moral, nuestra jurisprudencia ha señalado que "Todo daño patrimonial o no patrimonial es susceptible de ser cuantificable, puesto que para ello se puede utilizar diversos mecanismos auxiliares del Derecho, como son los informes contables, económicos, de rentabilidad de negocio e incluso, podría efectuarse un análisis costo-beneficio, dependiendo de las necesidades del proceso y de las circunstancias o elementos del mismo" 55 .

Asimismo, la doctrina ha señalado que para determinar el quantum de la reparación civil por daño moral debe cumplirse con los siguientes requisitos: "a) gravedad del delito que es tanto más intensa cuanto mayor es la participación del responsable en la comisión del hecho ilícito; b) la intensidad de la perturbación anímica, en la cual se debe tener en cuenta la duración del dolor, a la edad y al sexo del dañado; c) la sensibilidad de la persona ofendida; la Corte de Casación tiene en cuenta el nivel intelectual y moral de la víctima, y cuando éste es más alto - en opinión de los jueces, más grande es el dolor; d) las condiciones económicas y sociales de las partes, este parámetro, sin embargo, ha sido superado en los pronunciamientos más recientes porque contrasta con el sentimiento humano y con el principio de igualdad; el vínculo matrimonial o de parentesco; f) el estado de convivencia (entre parientes legítimos); a los convivientes de hecho, como se ha dicho, la orientación aún largamente mayoritaria de la jurisprudencia, niega también el resarcimiento del daño no patrimonial" ${ }^{\prime 56}$.

el daño moral la indemnización se fija sin ningún elemento que permita traducir la entidad de aquel en la magnitud de ésta, que se coloca a su lado". Vid. MéNDEZ Rozo, Diana Cecilia. Op. cit., p. 104.

54 Casación No. 1070-95-Arequipa, 13 de julio de 1998.

55 Casación No. 3220-2002-Camaná. 25 de abril de 2003.

56 Palacios MeléndeZ, Rosario Solange. "Derechos Humanos, Proceso Penal y Reparación Civil". En: Responsabilidad Civil II. Hacia una unificación de criterios de cuantificación de los daños en materia civil, penal y laboral. Lima: Editorial Rodhas, 2006, p. 52. 
No obstante, desde nuestra perspectiva, consideramos que para determinar el quantum de la reparación civil deberá analizarse: a) la gravedad del daño ocasionado, b) la intensidad de la perturbación anímica, c) la sensibilidad de la persona perjudicada o agraviada, d) la relación existente entre el agraviado y su agresor.

De esta manera, se aprecian los mecanismos de los cuales se podría servir el juzgador al momento de establecer una consecuencia jurídica satisfactoria, de carácter económico, destinada a indemnizar el daño moral. No obstante, debemos advertir que si bien el dinero no logra ser directamente proporcional con el daño moral ocasionado, sí puede entenderse como una manera de compensación que permita restablecer el estado anterior al daño ${ }^{57}$.

\section{CONCLUSIONES}

Finalmente, podemos señalar que si bien el Acuerdo Plenario No 6-2006/CJ116 señala que sí es posible la imposición de una reparación civil en casos de delitos de peligro, consideramos que es necesario analizar con profundidad los alcances de éste con la finalidad de determinar si es posible una reparación civil en los delitos de peligro concreto y abstracto, y más aún si estos pueden ser reparados en razón de "lucro cesante", "daño emergente", "daño a la persona" y "daño moral".

El análisis jurídico del presente trabajo nos permite determinar que sí es posible la reparación civil por daño moral en los delitos de peligro concreto y establecer el quantum de reparación civil por daño moral.

Asimismo, sugerimos que la Corte Suprema de Justicia debe elaborar un Acuerdo Plenario, Circular o Resolución en la cual establezca los criterios jurídicos para determinar el monto de reparación civil en los casos de daño moral.

\footnotetext{
57 “Si bien el dinero es algo muy diferente a los sentimientos, a lo espiritual de la persona, no es un fin en sí mismo sino un medio, tal vez el más apto para conseguir otros bienes que hagan a la comodidad, satisfacción o felicidad de las personas. En esa dimensión debe estar el dinero integrando la reparación del daño".
} 


\section{REFERENCIAS BIBLIOGRÁFICAS}

De TRAZEGNiES, Fernando. "La Responsabilidad Extracontractual." Lima: Fondo Editorial de la Pontificia Universidad Católica del Perú, 1988.

DíEZ- PicAzo y PONCE De LEÓN, Luis. Derecho de daños. Madrid: Editorial Civitas, 2000.

EsPINOZA EsPINOZA, Juan. Derecho de la Responsabilidad Civil. Lima: Editorial Grijley, 2006.

Etcheberry, Alfredo. Derecho Penal. Parte General. Tomo Segundo. Santiago de Chile: Carlos E. Gibbs A., Editor, 1964.

FOnTÁn BALESTRA, Carlos. Derecho penal. Introducción y Parte General. Buenos Aires: Abeledo-Perrto, 1998.

GUILLERMO BRINGAS. Luis Gustavo. "Aspectos fundamentales del resarcimiento económico del daño causado por el delito". Lex. Revista de Derecho. № 1. Lima, UIGV.

LARENZ, Karl. Derecho de obligaciones, Traducción de J. Santos Briz. Madrid: Revista de derecho Privado, 1959.

LEÓN, Lyesser. "Funcionalidad del "daño moral" e inutilidad del "daño a la persona" en el derecho civil peruano". Diké. Portal de Información y Opinión Legal de la Pontificia Universidad Católica del Perú. Disponible en Internet: http://dike.pucp.edu.pe/doctrina/civ_art57.PDF

MÉndez Rozo, Diana Cecilia. “El daño moral como límite a la libertad de prensa (Reflexiones desde el Derecho colombiano y el Derecho comparado)". REDUR. Diciembre. 1999. No. 7.

MuÑoz CONDE, Francisco y Mercedes GARCÍA ARÁN. Derecho Penal. Parte General. $2^{\circ}$ edición. Valencia: Tirant lo Blanch, 1996.

Osterling PARODI, Felipe. Tratado de Obligaciones. Lima: Gaceta Jurídica, 2005.

PAlacios Meléndez, Rosario Solange. “Derechos Humanos, Proceso Penal y Reparación Civil”. En: ESPINOZA ESPINOZA, Juan. (Comp.). Responsabilidad 
Flor de María Madelaine Poma Valdivieso

La reparación civil por daño moral en los delitos de peligro concreto

Civil II. Hacia una unificación de criterios de cuantificación de los daños en materia civil, penal y laboral. Lima: Editorial Rodhas, 2006.

Peña CABrera Freyre, Alonso. "Naturaleza jurídica de la reparación civil ex delicto". Gaceta Penal \& Procesal Penal. 2010. Nº 9.

REYNA AlFARO, Luis Miguel. "Estudio final: la víctima en el sistema penal". En: ReYNA AlFARO, Luis Miguel (Coord.) La víctima en el sistema penal. Dogmática, proceso y política criminal. Lima: Editorial Jurídica Grijley, 2006.

Sentencia recaída en el Exp. $N^{\circ} 411-2008$, de fecha once de setiembre del año dos mil ocho.

SALINAS SICCHA, Ramiro. Derecho Penal. Parte Especial. Quinta edición. Lima: Editorial Jurídica Grijley, 2013.

STC Nº0001-2005-AI, segundo párrafo del fundamento jurídico 17.

Sentencia del Exp. No 6872-97, Ej. sup., 27 dic. 1997. En: LA RosA GómEZ DE LA TORRE, jurisprudencia del proceso penal sumario, 1997. Lima, Editorial Jurídica Grijley, 1999.

SILva SÁnchez, Jesús-María. "¿"ex delicto"? Aspectos de la llamada "responsabilidad civil" en el proceso penal". INDRET. Julio. 2001. Disponible en Internet: www.indret.com

SILVA SÁNCHEZ, Jesús-María. "Sobre la relevancia jurídico-penal de la realización de actos de "reparación". En: REYNA ALFARO, Luis Miguel (Coord.). Victimología y Victimodogmática. Una aproximación al estudio de la Víctima en el Derecho Penal. Lima: ARA Editores, 2003.

TORRES VÁsqueZ, Aníbal. Diccionario de Jurisprudencia Civil. Lima: Editora Jurídica Grijley, 2008.

VAlderrama Moya, Karina Haydee. “Fundamentos para la cuantificación del Daño Moral”. Revista ESDEN. Agosto/Octubre. 2007. Año: 1, No. 2.

Velásquez VelásQueZ, Fernando. Derecho penal. Parte general. Bogotá: Editorial Temis, 1997.

VidAl LA Rosa SÁNCHEZ, María Delifna. "La reparación civil ex delicto en los delitos de peligro abstracto". Ágora. Revista de Derecho. 2007-2008. Años IV-VI, Ns 7 y 8. 
Vielma MendozA, Yoleida. "Discusiones en torno a la reparación del daño moral". Dikaiosyne. No. 16. Revista de filosofía práctica. Mérida: Universidad de Los Andes, 2006.

Villavicencio Terreros, Felipe. Derecho Penal. Parte General. Lima: Editorial Jurídica Grijley, 2006.

VILLAVICENCITO TERREROS, Felipe y Robert MEZA RIVERA. Informe legal. Análisis del delito de Atentado contra las condiciones de seguridad e higiene industriales. Disponible en Internet: www.vmrfirma.com

Zaffaroni, Eugenio Raúl. Manual de Derecho Penal Parte General. Lima: Ediciones Jurídicas, 1990.

ZAMORA BARBOZA, Juan Rodolfo. “La determinación judicial de la reparación civil". Actualidad Jurídica. $\mathrm{N}^{\circ} 184$.

\section{JURISPRUDENCIA CONSULTADA}

Acuerdo plenario $\mathrm{N}^{\circ}$ 6-2006/CJ-116, Precedente vinculante, Pleno Jurisdiccional de las Salas Penales Permanentes y Transitorias, 13 oct. 2006, Jurisprudencia. Año XV, No 857 [Boletín de El Peruano]. Lima, 29 dic. 2006, p. 6327.

Casación No. 3973-2006-Lima. 13 de diciembre de 2006.

Casación No. 1545-3006-Piura; Sala Civil de la Corte Suprema, Lima, 14 de noviembre de 2006.

Casación No. 1070-95-Arequipa, Sala Civil de la Corte Suprema, 13 de julio de 1998.

Casación No. 1070-95-Arequipa, 13 de julio de 1998.

Casación No. 3220-2002-Camaná. 25 de abril de 2003. 